\title{
A comparative study of oxytocin, carboprost, methylergometrine and misoprostol in prevention of postpartum haemorrhage a prospective study
}

\author{
Patil A.S. ${ }^{1}$, Dandavate V. ${ }^{2}$, Thobbi V. ${ }^{3}$ \\ ${ }^{1}$ Dr. Ambika S. Patil, Assistant Professor, ${ }^{2}$ Dr. Vibhavaree Dandavate, Associate Professor, ${ }^{3}$ Dr. Vidya Thobbi, Professor \\ and HOD, all authors are affiliated with Department of OBG, Al Ameen Medical College, Vijayapur, Karnataka, India.
}

Corresponding Author: Dr. Vibhavaree Dandavate, Associate Professor, Department of OBG, Al Ameen Medical College, Vijayapur, Karnataka, India. E-mail: vibhavaree.dandavate@gmail.com

\begin{abstract}
Background: Post partumhemorrhage (PPH) is an important cause of maternal mortality accounting for nearly $15-20 \%$ of maternal deaths in India. Oxytocic drugs like oxytocin, ergot alkaloids, and various prostaglandins are being used for active management of third stage of labour. Materials and Methods: A prospective study was conducted in the Department of Obstetrics and Gynaecology of Al Ameen Medical College, Vijayapur, in 400 women. Patients were randomized into four groups of 100 each and were given oxytocic within 60 seconds of delivery anterior shoulder of the baby. Oxytocics used were $10 \mathrm{IU}$ intramuscular oxytocin, $125 \mu \mathrm{g}$ intramuscular carboprost, $0.2 \mathrm{mg}$ intravenous methylergometrine, and $800 \mu \mathrm{g}$ tablet misoprostol per rectally in groups A, B, C and D respectively. Results: Duration of third stage of labor recorded was minimum with carboprost with mean duration of 3.84+/-0.99 minutes and was maximum with methylergometrine with mean duration of 5.04+/-1.02 minutes. Amount of blood loss observed was minimum with carboprost (mean $131+/-72.037 \mathrm{ml}$ ) and maximum with Methylergometrine (mean 435+/-147.578 ml). Hemoglobin drop was also seen more with Methylergometrine with mean drop of $0.872+/-0.458$ gm $\%$ and minimally with carboprost with mean drop of $0.236+/-0.221 \mathrm{gm} \%$. Conclusion: It is concluded from this study that carboprost is the uterotonic of choice followed by oxytocin for active management of third stage of labor.
\end{abstract}

Keywords: Postpartum Hemorrhage, Active Management of Third Stage of Labor, Oxytocic Drugs, Third stage of labour.

\section{Introduction}

The third stage of labour is the most crucial stage, begins with expulsion of baby and ends with expulsion of placenta and membranes. Its average duration is 15 min in both primigravida and multigravida [1]. Postpartum hemorrhage is one of the dreaded complications of third stage of labour. In India every 4 minutes a woman dies during childbirth [2]. Maternal mortality rate in India is 212 per 100000 live births. Among them $30 \%$ of deaths are due to postpartum hemorrhage $(\mathrm{PPH})[3]$.

Reducing likelihood of postpartum haemorrhage by routine active management of third stage of labour could play an important role in reducing maternal mortality and morbidity in modern obstetrics. The

Manuscript received: $10^{\text {th }}$ March 2019

Reviewed: $20^{\text {th }}$ March 2019

Author Corrected: $25^{\text {th }}$ March 2019

Accepted for Publication: $29^{\text {th }}$ March 2019 decrease in the problems associated with third stage of labour has been attributed to judicious use of different oxytocic preparations administered at time of delivery of anterior shoulder and a transition from expectant to active intervention [4-5]. Drugs conventionally used for prophylaxis against PPH includes oxytocin, methylergometrine, misoprostol and 15 methyl PGF2 $\alpha$ (Carboprost) [6]. Recent studies have shown that there are still wide variations in practice around the world in the management of third stage of labour [7-8].

Prophylactic use of oxytocic agents after delivery of the infant has been shown to reduce the incidence of PPH by $40 \%$. But it is associated with side effects ranging from nausea, vomiting, and hypertension to postpartum eclampsia, intracerebral haemorrhage, myocardial infarction, cardiac arrest and pulmonary oedema [2]. Carboprost tromethamine is a PGF2 $\alpha$ analogue. It is 


\section{Original Research Article}

given as a single intramuscular injection. It is free from side effects such as hypertension [9]. Postpartum haemorrhage is defined as any amount of bleeding following delivery which can lead to deterioration in the condition of woman.

It is difficult to delineate the risk factors for postpartum haemorrhage. So, all woman are considered at risk. Active management of third stage of labor has been universally recommended as not an option but a rule.

This includes administration of uterotonics, controlled cord traction and fundal massage the placenta will be delivered safely after the delivery of fetus and can prevent postpartum haemorrhage and maternal deaths.

\section{Aims and Objectives}

1. To evaluate and compare the efficacy of oxytocin, carboprost, methylergometrine and misoprostol in the active management of third stage of labor and thereby prevention of $\mathrm{PPH}$.

2. To compare the amount of blood loss in third stage.

3. To compare the duration of third stage.

4. To evaluate the side effects

\section{Methods}

The present prospective study was conducted in the Department of Obstetrics and Gynaecology, Al Ameen Medical College, Vijayapur, over the period from 2017 to 2018 after taking approval from Institutional Ethical Committee. Four hundred patients were enrolled and these patients were distributed in four different groups randomly.

Informed consent and counselling of the patients was done. A detailed history of all the patients was taken including name, age, parity, socioeconomic status, and menstrual history, period of gestation (in weeks), obstetrical history including postpartum hemorrhage and history of any medical disorder. Complete general and systemic examination was done. Detailed systemic and obstetrical examination was done. Pelvic examination was done.

After detailed history and examination, patients were randomized into four groups of 100 each as follows:

Group A- Patients received 10 IU intramuscular oxytocin.

Group B- Patients received $125 \mu \mathrm{g}$ intramuscular carboprost
Group C- Patients received $0.2 \mathrm{mg}$ intravenous methylergometrine.

Group D- Patients received $800 \mu \mathrm{g}$ tablet misoprostol per rectally.

Placebo control is not possible in this study because we can't deny a uterotonic to a patient after delivery.

Inclusion Criteria: Women with singleton pregnancy, Term gestation, without any high risk factors.

\section{Exclusion Criteria}

1. Period of gestation $<37$ weeks and $>42$ week.

2. Fetal complications: IUFD, IUGR.

3. Maternal complications: PIH, Multiple pregnancy, Grand multipara, APH, malpresentations, patient with known blood coagulation disorder, patient with known allergy to prostaglandins, history of medical disorderscardiac disease/renal disease, anemia $(\mathrm{Hb}<7 \mathrm{gm} \%)$

Active management of third stage of labor was done within one minute after the birth of the baby using one of the four oxytocic drugs as per the group of the patient.

Within a minute of delivery of baby, Brass-V drapes were immediately applied to measure the amount of blood loss. Placenta was delivered by controlled cord traction as soon as signs of placental separation appeared. Inspection of vulva for perineal tears and per speculum examination for cervical tear was carried out and if present patients were not taken into series. Repeat haemoglobin estimation was done on second postpartum day.

Type of study: Prospective study.

Ethical Approval: The study was approved by the institutional ethics committee.

Sampling Method: Randomisation done.

Statistical Methods: The statistical analysis was performed using students t-test and paired t-test for continuous variables. $p$-value of $<0.05$ was considered statistically significant. Data were calculated as means, standard deviation (SD), numbers and frequency (\%). No scoring system and surgical procedure used.

The data were evaluated for the following

1. Duration of third stage of labor in all groups.

2. Amount of blood loss during third stage of labor.

3. Drop in mean hemoglobin levels in various groups.

4. Comparison of the side effects of various uterotonics. 


\section{Results}

Patients in all four groups were comparable with regards to their age, socioeconomic status, parity, booking status, BMI and number of episiotomies given (Table1).

Mean duration of third stage of labor was 4.72 minutes in group A, 5.04 minutes in group C and 4.93 minutes in group D. It was lowest in group B (3.84 minutes) which is statistically significant with p value of 0.002 (Table2) (Graph1).

Mean blood loss in various study groups A, B, C and D was 223.2, 131.8, 435 and 255.8ml respectively. Maximum blood loss was in patients given methylergometrine and minimal in patients given Carboprost with a p-value of $<0.001$ which is statistically significant (Table 2) (Graph 2).

Groups A, B and D showed comparable drop in haemoglobin 0.3, 0.2 and 0.4 gm\%. The maximal drop was observed in group $\mathrm{C}$ up to $0.8 \mathrm{gm} \%$ with a significant p-value of 0.002 (Table2).

However 6 patients in group C had postpartum hemorrhage (statistically significant with p-value of 0.004) (Table 2).

Two patients out of six who had postpartum haemorrhage necessitating additional oxytocics and blood transfusion which is statistically significant with a p-value of 0.111 (Table 2).

Nausea and vomiting were found to be the commonest side effects in all groups followed by shivering and fever.

Table-1: Biosocial characteristics of the study subjects.

\begin{tabular}{|c|c|c|c|c|c|}
\hline & Group A & Group B & Group C & Group D & p-value \\
\hline Mean age (years) & 22.96 & 22.16 & 22.84 & 23.16 & 0.051 \\
\hline \multicolumn{6}{|l|}{ Booking $(\%)$} \\
\hline Booked & 52 & 48 & 44 & 52 & \\
\hline Unbooked & 48 & 52 & 56 & 48 & 0.931 \\
\hline \multicolumn{6}{|c|}{ Socioeconomic status (\%) } \\
\hline Upper & 0 & 0 & 0 & 4 & \\
\hline Upper middle & 36 & 32 & 36 & 44 & 0.921 \\
\hline Lower middle & 44 & 40 & 40 & 36 & \\
\hline Upper lower & 12 & 24 & 20 & 12 & \\
\hline Lower & 8 & 4 & 4 & 4 & \\
\hline \multicolumn{6}{|l|}{ Parity $(\%)$} \\
\hline $\mathrm{P} 1$ & 64 & 72 & 76 & 56 & 0.803 \\
\hline P3 & 8 & 8 & 12 & 20 & \\
\hline \multicolumn{6}{|l|}{ BMI (\%) } \\
\hline$<18.50$ & 8 & 8 & 0 & 0 & \\
\hline $18.50-24.99$ & 84 & 84 & 100 & 96 & \\
\hline 25.00-29.99 & 8 & 4 & 0 & 0 & 0.286 \\
\hline $30.00-34.99$ & 0 & 4 & 0 & 0 & \\
\hline $35.00-39.99$ & 0 & 0 & 0 & 4 & \\
\hline$\geq 40$ & 0 & 0 & 0 & 0 & \\
\hline \multicolumn{6}{|l|}{ Episiotomy (\%) } \\
\hline Given & 80 & 72 & 84 & 64 & 0.369 \\
\hline Not given & 20 & 28 & 16 & 36 & \\
\hline
\end{tabular}


Original Research Article

Table-2: Post-delivery data in four groups.

\begin{tabular}{|l|c|c|c|c|c|}
\hline & $\begin{array}{c}\text { Group A } \\
\text { Oxytocin }\end{array}$ & $\begin{array}{c}\text { Group B } \\
\text { Carboprost }\end{array}$ & $\begin{array}{c}\text { Group C } \\
\text { Methylergometrine }\end{array}$ & $\begin{array}{c}\text { Group D } \\
\text { Misoprostol }\end{array}$ & $\begin{array}{c}p \text { - } \\
\text { value }\end{array}$ \\
\hline $\begin{array}{l}\text { Duration of third stage of } \\
\text { labor (minutes) }\end{array}$ & 4.72 & 3.84 & 5.04 & 4.93 & 0.002 \\
\hline Amount of blood loss (ml) & 223.2 & 131.8 & 435 & 255.8 & $<0.000$ \\
\hline $\begin{array}{l}\text { Drop in hemoglobin } \\
\text { (gm\%) }\end{array}$ & 0.372 & 0.236 & 0.872 & 0.44 & $<0.000$ \\
\hline $\begin{array}{l}\text { Number of patients having } \\
\text { blood loss > 500 ml }\end{array}$ & 0 & 0 & 6 & 0 & 0.0004 \\
\hline $\begin{array}{l}\text { Number of patients } \\
\text { requiring blood transfusion }\end{array}$ & 0 & 0 & 2 & 0 & 0.111 \\
\hline
\end{tabular}

\section{Discussion}

Postpartum hemorrhage is one of the most important cause for maternal deaths throughout the world. Active management of third stage of labor and the use of prophylactic oxytocics has reduced its incidence in many countries. The primary aim in the management of postpartum hemorrhage should be its prevention. The active management of the third stage with routine prophylactic administration of oxytocics at the time of delivery of the anterior shoulder of the fetus has been shown to reduce the risk of postpartum hemorrhage by about $40 \%[5,10]$.

Recent studies show that there are still wide variations in practice around the world in the management of third stage of labour. Methyl ergometrine is a conventional oxytocic used extensively but is associated with unpleasant side effects like hypertension. Intramuscular oxytocin used alone has been found effective in preventing postpartum hemorrhage with fewer side effects and is recommended by world health organization but most of the times additional uterotonics are required [8,11]. Various drugs and routes of administration have been tested with varying success. Oxytocin is probably the most commonly used oxytocic and has been well known in midwifery for a long time. Though commonly used it is not the potent drug and many a times requires additional drugs and blood loss is more compared with other drugs [11].

The production of PGF $2 \alpha$ in the decidual tissue was found to be more when obtained during labour indicating the increase in the synthesis and release of PGF2 $\alpha$ into the circulation. PGF $2 \alpha$ is a powerful uterotonic agent with a physiological role in human parturition both in the delivery of the foetus and control of post partum bleeding. The discovery of prostaglandins and its analogues as an oxytocics has improved prospect in modern era in control of PPH due to its significant influence on uterine tone resulting in minimizing blood loss which outweighs its cost. The side effects are also subtle [12-13]. Hence this study was conducted at Al Ameen medical college to evaluate the four uterotonic drugs. This study has shown that that carboprost is the uterotonic of choice followed by oxytocin for active management of third stage of labor.

Table-3: Mean duration of third stage

\begin{tabular}{|c|c|c|c|c|}
\hline Study & Methyl ergometrine & Carboprost & Oxytocin & Misoprostol \\
\hline Singh nisha etal [20] & 5.52 minutes & 6.10 minutes & - & \\
\hline Anjaneyu etal [13] & 6.1 minutes & 3.5 minutes & - & \\
\hline Bhattacharya et al [4] & 8.08 minutes & 4.8 minutes & - & \\
\hline B. Rajupuroshotam etal [19] & 3.6 minutes & 2.63 minutes & - & \\
\hline Present study & 5.04 minutes & 3.84 minutes & 4.72 minutes & 4.93 minutes \\
\hline
\end{tabular}

There are few studies where carboprost has been compared with methyl ergometrine and found that the mean duration of third of labour with carboprost was comparable to our study [14,15]. As compared to other studies and in accordance with it, the present study showed decrease in mean duration of third stage of labor incarboprost group was 3.84 minutes compared to oxytocin 4.72 minutes. Therefore carboprost can be effective in reducing the duration of third stage of labour. 
Original Research Article

Table-4: Comparison of estimated blood loss in $\mathrm{ml}$.

\begin{tabular}{|c|c|c|c|c|}
\hline Study & $\begin{array}{c}\text { Methyl } \\
\text { ergometrine }\end{array}$ & Carboprost & Oxytocin & Misoprostol \\
\hline Reddy et al [14] & $202 \mathrm{ml}$ & $127 \mathrm{ml}$ & - & \\
\hline B. Rajupuroshotam [19] & $169 \mathrm{ml}$ & $111 \mathrm{ml}$ & - & \\
\hline Present study & $435 \mathrm{ml}$ & $131.8 \mathrm{ml}$ & $223.2 \mathrm{ml}$ & $255.8 \mathrm{ml}$ \\
\hline
\end{tabular}

Various studies have shown that the mean blood loss with carboprost $125 \mu \mathrm{g}$ was less compared to methyl ergometrine. Few studies compared carboprost with syntometrine, which did not show any difference in mean blood loss in both the group [14]. In the present study mean blood loss in third stage in carboprost was $131.8 \mathrm{ml}$ and oxytocin was $223.2 \mathrm{ml}$. ( $p$ value of 0.0001) which was highly significant [11]. None of them developed PPH in carboprost group but 6 women had PPH in methylergometrine group. This was comparable with other studies as shown in the table. Hence carboprost is effective in reducing blood loss and carboprost has sustained impact on tone of uterus. Hemoglobin was 0.3 in oxytocin and 0.23 carboprost, $0.87 \mathrm{gm} \%$ in methylergometrine group, $0.44 \mathrm{gm} \%$ in misoprostol group which was statistically significant ( $\mathrm{p}$ value of 0.0001 ). Two required blood transfusion in methylergometrine group and none in other 3 groups.

In group A, minor side effects in the form of shivering, vomiting and headache were observed. Our findings are not consistent with that of Gohil J et al (2011) as the incidence of these minor side effects was much lowerintheir study [21].

In group B Diarrhea and vomiting were most commonly observed inalong with chills in only $12 \%$. This is comparable to the study of Chua S et al (1995) where they found a significant increase in the incidence of diarrhea with prostidin [24].

In group $C$ in addition to shivering and nausea, side effects like hypertension was also observed in $24 \%$ of patients, study being consistent with that of Gohil $\mathrm{J}$ et al (2011) as patients exhibited hypertension in their study also [21].

In group D, minor side effects, like shivering and fever, were present in $48 \%$ and $56 \%$ of patients. Our study is consistent with the study of El Refaey et al (1997), Hofmeyer G J et al (1998), F Amant et al (1999), Hazem El- Rafaey et al (2000) in which their patients also exhibited fever and shivering [22,23,25].

The only Drawback in using carboprost is its storage in cold chain at 2- 4 celsius while oxytocin can be stored at room temperature.

\section{Conclusion}

Carboprost when used prophylactically results in minimal blood loss with fewer side effects. This small dose $125 \mu \mathrm{g}$ is well tolerated by the patients. An added advantage is it can be used in patients with hypertension and cardiovascular disease. In India where anemia highly prevalent, the risk of PPH is very high.

Intramuscular carboprost, a potent uterotonic is a desirable drug as it is well tolerated in small doses and significantly reduces the risk of PPH by limiting duration of $3^{\text {rd }}$ stage of labour \& by reducing the blood loss Our study emphasizes that carboprost is better alternative to intramuscular oxytocin in active management of third stage of labour.

Acknowledgements- All my regards to my patients without whom the study was not possible and the ethical committee of Al Ameen medical college and my team in department of OBG.
Contribution by Co-Authors: Our corresponding author and second author are senior professor and experienced in this field, hence their guidance helped us in selecting the type of study in various discussions of cases and getting maximum number of study material and patients.

\section{What this study adds to existing knowledge:}

1. Our study proves that carboprost is most effective and well tolerated uterotonic in prevention of $\mathrm{PPH}$.

2. Lesser requirement of additional uterotonics and blood transfusion.

\section{Declarations}

Funding: Nil, Conflict of interest: Nil Permission from IRB: Yes

Ethical approval: The study was approved by the institutional ethics committee. 


\section{Original Research Article}

\section{References}

1.Mukherje J, Ganguly RP, Saha SK Maternal mortality due to hemorrhage with emphasis on post partum haemorrhage.J Obstet Gynecol India.2001;51(5):130-33

2. Christopher B. Lynch, Moore Keith. A textbook of postpartum hemorrhage, a comprehensive guide to evaluate management and surgical intervention. FOGSI publication 2006; 8 .

3. Park K. Preventive medicine in obstetrics, pediatrics and geriatrics, chapter 9 in textbook of preventive and social medicine, $22^{\text {nd }}$ edition. Jabalpur, M/S Banarri Das Bharot, 2013; 516-519.

4. Bhattacharya P, Devi PK, Jain S. Prophylactic use of 15 methyl PGF2 $\alpha$ by intramuscular route for control of post partum bleeding- A comparative trial with methylergometrine. Acta Obstet Gynecol Scand Suppl 1988; 145:13-5.

5. Prendiville $\mathrm{WJ}^{1}$, Elbourne D, McDonald S. Active versus expectant management in the third stage of labour. Cochrane Database Syst Rev. 2000; (3): CD 000007. DOI:10.1002/14651858.CD000007

6. Schuurmans N. Prevention and management of postpartum hemorrhage. J Soc Obstet Gynecol Can 2000; 22(4):271-281.

7. WHO department of making pregnancy safer 2009. WHO recommendations for treatment of $\mathrm{PPH}$ and retained placenta. WHO: Geneva. 2013. available from www.who.int.

8. Chelmow D. Postpartum hemorrhage prevention: clinical evidence. BMJ 2011; 1 - 6 .

9. Hofmeyr GJ, Gulmezoglu AM. New Development in the management of postpartum hemorrhageIn: Bonner. 21 st edn. London. Churchill Livingstone. J. Recent Advances in Obstetrics \& Gynaecology. 2000; 56-66.

10. FIGO. International confederation of midwives, international federation of gynecology and obstetrics (FIGO) 2006. Prevention and treatment of PPH, new advances for low resource settings. joint statement. ICM: The Hague :IFIGO:London2006.

11. Patel A, Goudar SS, Geller SE, et al. Drape estimation vs. visual assessment for estimating postpartum hemorrhage. Int J Gynaecol Obstet. 2006 Jun;93 (3):220-4. Epub 2006 Apr 12. DOI:10.1016/j. ijgo.2006. 02.014
12. Kamala Jayaram V, Devi ED. Prophylactic PGF2 $\alpha$ for control of postpartum bleeding a comparative study with methyl ergometrine. J Obstet Gynaecol Ind 1994; 44:393-97.

13. Anjaneyulu R, Pk D, Jain S, et al. Prophylactic use of 15 (s) 15 methyl pgf $2 \alpha$, by intramuscular route - a controlled clinical trial. Acta ObstetGynecol Scand. 1988 Jan; 67 (S145):9-11. doi: 10.1111/aogs. 1988. 67.s 145.9 .

14. Leduc D, Senikas V, Lalonde AB; et al. Active management of the third stage of labour: prevention and treatment of postpartum hemorrhage. J ObstetGynaecol Can. 2009 Oct; 31(10):980-993. doi: 10.1016/S17012163 (16)34329-8.

15. Leung SW, Ng PS, Wong WY, et al. A randomised trial of carbetocin versus syntometrine in the management of the third stage of labour. BJOG. 2006 Dec; 113(12):1459-64. DOI:10.1111/j.1471-0528.2006. 01105.x

16. Pk D, Ud S, Ks R. Prophylactic use of $15(\mathrm{~s}) 15$ methyl pgf $2 \alpha$ for control of postpartum bleeding. Acta Obstet Gynecol Scand. 1988 Jan;67(S145):7-8. doi: 10.1111/aogs.1988.67.s145.7.

17. Abdel-Aleem H, Abol-Oyoun EM, Moustafa SA, et al. Carboprost trometamol in the management of the third stage of labor. Int J Gynaecol Obstet. 1993 Sep;42 (3): $247-50$.

18. Kushtagi P, Verghese LM. Evaluation of two uterotonic medications for the management of the third stage of labor. Int J Gynaecol Obstet. 2006 Jul; 94(1): 47-8. Epub 2006 Jun 8. DOI: 10.1016/j.ijgo. 2006. 04. 011

19. Raju B, Purushotta, Patil R. 15 Methyl PGF2 alpha and ergometrine for prevention of atonic $\mathrm{PPH}$ in high risk women. J Obstet Gynecol India 2008; 58(5): 417-420

20. Singh G, Radhakrishnan G, Guleria K. Comparison of sublingual misoprostol, intravenous oxytocin, and intravenous methylergometrine in active management of the third stage of labor. Int J Gynaecol Obstet. 2009 Nov; 107 (2): 130-4. doi: 10.1016/j.ijgo. 2009. 06.007. Epub 2009 Jul 22. 


\section{Original Research Article}

21. Gohil JT, Tripathi B. A Study to Compare the Efficacy of Misoprostol, Oxytocin, Methyl-ergometrine and Ergometrine-Oxytocin in Reducing Blood Loss in Active Management of 3rd Stage of Labor. J Obstet Gynaecol India. 2011 Aug;61(4):408-12. doi: 10.1007/s 13224-011-0060-5. Epub 2011 Sep 23.

22. Tripti N, Balram S. $400 \mu \mathrm{g}$ oral Misoprostol versus $0.2 \mathrm{mg}$ intravenous Methyl ergometrine for the active management of third stage of labor. JOGI2009 May/June; 59(3):228-234.

23. Sorbe B. Active pharmacologic management of the third stage of labor.A comparison of oxytocin and ergometrine. Obstet Gynecol. 1978 Dec;52(6):694-7.
24. Amant F, Spitz B, Timmerman D, et al. Misoprostol compared with methylergometrine for the prevention of postpartum haemorrhage: a double-blind randomised trial. Br J Obstet Gynaecol. 1999 Oct; 106 (10): 1066-70.

25. Chua S, Chew SL, Yeoh CL, Roy AC, Ho LM, Selamat N, Arulkumaran S, Ratnam SS. A randomized controlled study of prostaglandin 15methyl F2 alpha compared with syntometrine for prophylactic use in third stage of labor. Aust NZJ Obstet Gynaecol 1995 Nov; 35 (4): 413- 416.

\section{How to cite this article?}

Patil A.S., Dandavate V, Thobbi V. A comparative study of oxytocin, carboprost, methylergometrine and misoprostol in prevention of postpartum haemorrhage a prospective study. Obs Rev: J obstet Gynecol 2019;5(2):99-105.doi:10.17511/ joog.2019.i02.03. 